\title{
Cooperating if one's Goals are Collective-Based: Social Identification Effects in Social Dilemmas as a Function of Goal-Transformation
}

\author{
David De Cremer, Daan van Knippenberg, Eric van Dijk \\ and Esther van Leeuwen
}

\begin{tabular}{|l|l|}
\hline \multicolumn{2}{|l|}{ ERIM REPORT SERIES RESEARCH IN MANAGEMENT } \\
\hline ERIM Report Series reference number & ERS-2007-010-ORG \\
\hline Publication & February 2007 \\
\hline Number of pages & 31 \\
\hline Persistent paper URL & \\
\hline Email address corresponding author & d.decremer@psychology.unimaas.nl \\
\hline Address & Erasmus Research Institute of Management (ERIM) \\
& RSM Erasmus University / Erasmus School of Economics \\
& Erasmus Universiteit Rotterdam \\
& P.O.Box 1738 \\
& 3000 DR Rotterdam, The Netherlands \\
& Phone: $\quad+31104081182$ \\
& Fax: $\quad+31104089640$ \\
& Email: info@erim.eur.nl \\
& Internet: $\quad$ www.erim.eur.nl \\
\hline
\end{tabular}

Bibliographic data and classifications of all the ERIM reports are also available on the ERIM website: www.erim.eur.nl 


\section{ERASMUS RESEARCH INSTITUTE OF MANAGEMENT}

\section{REPORT SERIES}

\section{RESEARCH IN MANAGEMENT}

\begin{tabular}{|l|l|}
\hline ABSTRACT AND KEYWORDS \\
\hline Abstract & $\begin{array}{l}\text { Prior studies of the effect of group identification on cooperation in social dilemmas have } \\
\text { advanced two competing accounts of this effect, the goal-transformation hypothesis, which holds } \\
\text { that identification implies a sense of collective self, which makes personal and collective goals } \\
\text { interchangeable, and the goal-amplification hypothesis, which states that identification induces } \\
\text { positive expectations about others' cooperative behavior. These prior studies have, however, } \\
\text { neglected to assess the process measures necessary to pit the one account against the other. } \\
\text { Following prior research, the present study showed that the effect of identification was } \\
\text { moderated by participants' social value orientation (i.e., individual differences in evaluating the } \\
\text { importance of outcomes for self and other) in such a way that identification influenced proselfs' } \\
\text { cooperation more than prosocials' cooperation. This suggests that the consequence of group } \\
\text { identification is that collective goals become personal goals. Extending earlier recent research, } \\
\text { mediational analyses showed that the effect of our identification manipulation was mediated by } \\
\text { participants' sense of collective self and not by their expectations. Taken together, these results } \\
\text { provide strong support in favor of the goal-transformation hypothesis. }\end{array}$ \\
\hline Free Keywords & Goal-transformation hypothesis, Goal-amplification hypothesis \\
\hline Availability & $\begin{array}{l}\text { The ERIM Report Series is distributed through the following platforms: } \\
\text { Academic Repository at Erasmus University (DEAR), DEAR ERIM Series Portal } \\
\text { Social Science Research Network (SSRN), SSRN ERIM Series Webpage } \\
\text { Research Papers in Economics (REPEC), REPEC ERIM Series Webpage }\end{array}$ \\
\hline Classifications & $\begin{array}{l}\text { The electronic versions of the papers in the ERIM report Series contain bibliographic metadata } \\
\text { by the following classification systems: } \\
\text { Library of Congress Classification, (LCC) LCC Webpage } \\
\text { Journal of Economic Literature, (JEL), JEL Webpage } \\
\text { ACM Computing Classification System CCS Webpage } \\
\text { Inspec Classification scheme (ICS), ICS Webpage }\end{array}$ \\
\hline
\end{tabular}




\title{
Running Head: COOPERATION AND COLLECTIVE GOALS
}

\section{Cooperating if one’s Goals are Collective-Based:}

Social Identification Effects in Social Dilemmas as a Function of Goal-Transformation

\author{
David De Cremer \\ Maastricht University \\ Daan van Knippenberg \\ Erasmus University Rotterdam \\ Eric van Dijk \\ University of Leiden \\ Esther van Leeuwen \\ Free University Amsterdam
}

Address correspondence to David De Cremer, Department of Experimental

Psychology, P.O. Box 616, 6200 MD Maastricht, The Netherlands, Email:

d.decremer@psychology.unimaas.nl, Fax: 0031433884196.

The first author was supported by a fellowship of the Netherlands Organization for Scientific Research (NWO, grant no. 016.005.019). 


\begin{abstract}
Prior studies of the effect of group identification on cooperation in social dilemmas have advanced two competing accounts of this effect, the goal-transformation hypothesis, which holds that identification implies a sense of collective self, which makes personal and collective goals interchangeable, and the goal-amplification hypothesis, which states that identification induces positive expectations about others' cooperative behavior. These prior studies have, however, neglected to assess the process measures necessary to pit the one account against the other. Following prior research, the present study showed that the effect of identification was moderated by participants' social value orientation (i.e., individual differences in evaluating the importance of outcomes for self and other) in such a way that identification influenced proselfs' cooperation more than prosocials’ cooperation. This suggests that the consequence of group identification is that collective goals become personal goals. Extending earlier recent research, mediational analyses showed that the effect of our identification manipulation was mediated by participants' sense of collective self and not by their expectations. Taken together, these results provide strong support in favor of the goal-transformation hypothesis.
\end{abstract}


Cooperating if one’s Goals are Collective-Based:

Social Identification Effects in Social Dilemmas as a Function of Goal-Transformation

A social dilemma can be defined as a situation in which personal and collective

interests are at odds (Dawes, 1980; Komorita \& Parks, 1994; Messick \& Brewer, 1983).

In its simplest form, a social dilemma represents an interdependence situation in which people have to decide independently to cooperate or not. Hence, each group member is confronted with a choice between two options, to cooperate or to defect. In these interdependence situations, the dominant choice is to act in one's own best interest, because the individual's incentives for not cooperating are greater than for cooperating, regardless of what others do (Dawes, 1980). However, if all group members opt for this dominant choice, all will end up worse than if all make the choice to cooperate.

Rational choice theories (e.g., Luce \& Raiffa, 1957) assume that people will pursue their own self-interest, and, therefore, cooperation in groups seems difficult to achieve. However, according to Edney (1980), "The truer perspective is that human beings probably have greater capacities for both socially constructive [i.e., collective interested] and destructive behaviors [i.e., based in self-interest] around resources” (p. 148). In other words, under specific situations, people may indeed be inclined to exhibit cooperative behavior in social dilemmas. One typical solution to this conflict between personal and collective interest, and one, which truly incorporates a social focus, is increasing the extent to which decision-makers identify with the collective.

The major purpose of the present research is to examine the psychological mechanisms underlying this social identification effect in social dilemmas by focusing on the role of two psychological variables that may account for this effect: Expectations 
about other group members' cooperation, and the sense of collective self inherent in social identification. Following recent research (e.g., De Cremer \& Van Vugt, 1999), this was investigated by examining the interaction of social identification with individuals' social value orientation. In an important extension of this earlier research, we also assessed the mediating roles of group members' expectations of others' cooperation and of the sense of collective self that is inherent in identification.

\section{Social Identification Effects in Social Dilemmas}

A number of studies and reviews have concluded that the extent to which individual decision-makers define themselves in terms of their group membership may function as a reference point for their decision behavior (Brewer \& Schneider, 1990; Kramer \& Brewer, 1986). When affiliation with the group or collective is reinforced, "the group is the basis of cooperation” (Turner, 1987; p. 34). Empirical studies have indeed shown that when people exhibit strong group identification, relative to weak group identification, people invest more in public good dilemmas and exercise greater restraint in resource dilemmas (Brewer \& Kramer, 1986; De Cremer \& Van Vugt, 1999; De Cremer \& van Dijk, 2002; Kramer \& Brewer, 1984; Kramer \& Goldman, 1995, Wit \& Wilke, 1992). Yet, up until now, it still is not clear how exactly social identification effects produce this collectively desirable behavioral outcome.

We argue that, because of the specific nature of the social dilemma conflict in which one's individual interest is plotted against the collective interest, two processes may be particularly important. First, in social dilemmas decision-makers may fear to be exploited by the others and to end up as the "sucker" (Kerr, 1983). Therefore, to increase cooperation, this element of risk should be reduced; a situation that can be achieved by 
increasing people's expectations that the others will cooperate (De Cremer, Snyder, \& 2001; Pruitt \& Kimmel, 1977). As positive expectations increase, confidence in the goodwill of others and fear of exploitation is reduced, lowering the threshold to engage in cooperation (De Cremer et al., 2001; Van Leeuwen \& van Knippenberg, 2002). Research on intergroup relations suggests that an enhanced sense of group identification may produce more positive expectations toward other ingroup members, relative to outgroup members (i.e., ingroup favoritism; Tajfel \& Turner, 1986). For example, Brewer (1979) argued that ingroup members are judged as more trustworthy and honest than outgroup members, particularly when group identity is reinforced (Brewer, 1979); a process also referred to as group-based trust (Brewer, 1981). A first explanation of the social identification effect in social dilemmas thus is that higher identification is associated with more positive expectations about the cooperation of others, and that these expectations invite own cooperation.

A second explanation lies in the merging of self and group that is inherent in social identification. Social identification reflects a sense of oneness with the group, where the self is defined in terms of membership in, and characteristics of the group (e.g., Hogg \& Abrams, 1988; Smith \& Henry, 1996; Turner, 1987). The more the self is defined in collective terms (i.e., the collective self; Brewer \& Gardner, 1996; Turner, 1987), the more collective goals will be experienced as the own goals, and collective interests as self-interests (i.e., collective self-interests rather than personal self-interests; De Cremer \& Van Vugt, 1999; van Knippenberg, 2000; van Knippenberg \& Ellemers, in press; cf. Brewer, 1991). Accordingly, the higher group identification, the less likely it will be that motives like greed and free riding (i.e., which are rooted in the personal self- 
interest) will dominate decisions (cf. Rapoport, 1967), and, therefore, the higher the level of cooperation. The second explanation of the social identification effect in social dilemmas thus is that high compared with low identification is associated with a different definition of self and as a consequence with a different definition of self-interest.

To summarize, then, the literatures on social dilemmas and social identification suggest two processes that may account for the effect of social identification on cooperation in social dilemmas: The effect of identification may be caused by its influence on expectations about others' cooperation or it may be caused by the sense of collective self (which will make personal and collective goals interchangeable) that is inherent in identification. Both processes should be able to reduce the influence of two dominating motives in social dilemma situations, fear and greed. Recent research attempted to answer the question of which of the two processes primarily underlies the cooperation-enhancing effect in social dilemmas by examining the interaction between social identification and group members’ social value orientation (SVO; De Cremer \& Van Vugt, 1999; De Cremer \& van Dijk, 2002; Kramer \& Goldman, 1995). Social value orientations are individual differences in how people evaluate outcomes for themselves and others in interdependent situations (McClintock, 1972; Messick \& McClintock, 1968). Broadly speaking, people can be classified as prosocial individuals (i.e., aimed at maximizing joint outcomes and equality in outcomes), competitors (i.e., aimed at maximizing the difference between outcomes for self and other) or individualists (i.e., aimed at maximizing own outcome, regardless of other's outcome). The latter two are usually referred to as proselfs (Van Lange \& Liebrand, 1991). Previous research on this individual difference variable has convincingly demonstrated that prosocials exhibit more 
cooperative behavior than proselfs and express a greater concern with the group as a whole (e.g., De Cremer \& Van Lange, 2001; Van Vugt, Meertens, \& Van Lange, 1995).

The interactive effects of identification and SVO is especially diagnostic in the study of the effects of social identification on cooperation in social dilemma, because social value orientations are related to expectations of others' cooperation as well as to the weight attached to the own self-interest. First, if identification would enhance positive expectations, then particularly prosocials would be influenced in their behavior. This prediction was derived from two social dilemma findings. According to Pruitt and Kimmel's goal-expectation theory (1977), two conditions have to be met to elicit cooperation, that is, (a) one should have a pro-social or cooperative goal, and (b) one should expect others to cooperate. Second, prosocials, relative to proselfs, believe that others cooperate more, but they also expect some variability in levels of cooperation across persons (Kelley \& Stahelski, 1970; see also Van Lange, 1999). Positive expectations that others will cooperate should thus reduce this variability in expectations among prosocials, but not among proselfs. Thus, if a strong sense of group identification reinforces positive expectations then particularly those with an initial prosocial goal (i.e., a sense of collective self), should be influenced most in their contribution behavior, what we refer to as the goal-amplification hypothesis (De Cremer \& Van Vugt, 1999).

This hypothesis can be contrasted with the argument of De Cremer and colleagues (De Cremer \& Van Dijk, in press; De Cremer \& Van Vugt, 1999; see also van Knippenberg, 2000) that if group identification affects people's sense of collective self, and therefore the definition of self-interest (i.e., shifting from personal to collective selfinterest), particularly the decisions of proselfs should be influenced. From the social 
value orientation literature follows that proselfs as compared with prosocials assign more weight to outcomes for self than to outcomes for others (e.g. McClintock, 1972). As a consequence of this dispositional difference in the weight assigned to the self-interest, proselfs' behavior should be more contingent on factors that influence the definition of the self-interest, such as identification is proposed to do. Brewer (1979) argued that a strong sense of identification promotes group-oriented actions, because "the reduced differentiation between one’s own and others’ outcomes associated with ingroup formation provides one mechanism for increasing the weight given to collective outcomes in individual decision-making” (p. 322). Elaborating these insights, it can be predicted that group identification, due to an enhancement of people’s sense of collective self, should influence contribution behavior more among proselfs than among prosocials; we call this the goal-transformation hypothesis (De Cremer \& Van Vugt, 1999).

Studies employing this identification by social value orientation approach have yielded first evidence in favor of the goal-transformation hypothesis. For example, De Cremer and Van Vugt (1999) demonstrated in a series of public good dilemma studies that proselfs were most strongly influenced by manipulations of group identification, an effect that was replicated by De Cremer and Van Dijk (2002), who showed that this effect is particularly strong when people lack information about prior failure or success (see also Kramer \& Goldman, 1995, for some partial evidence). However, although these reported interactions between identification and SVO provide us with a strong (theoryderived) indication in favor of the goal-transformation hypothesis, no research to date has also examined the process variables that are assumed to underlie this interaction effect. This is problematic, because finding behavioral effects consistent with the proposed 
hypothesis does not necessarily mean that the associated processes do occur as well.

Therefore, for a proper test of the merits of the goal-amplification and goal-

transformation hypotheses, it is necessary that the proposed mediating processes of the social identification effect are examined in addition to behavioral measures.

Such was the aim of the present study. In the present study, we extended earlier research on the interaction of social identification and social value orientation in social dilemmas with two key process measures: A measure of expectations of others' cooperation and a measure of identification. The former may be affected by manipulations of identification, the latter, of course, should be affected by manipulations of identification. Of critical importance, the goal-amplification hypothesis requires that the former mediates the effect of manipulations of identification, whereas the goaltransformation hypothesis requires that the latter mediates the effect of manipulations of identification on cooperation. Based on De Cremer and Van Vugt's (1999) findings in support of the goal-transformation hypothesis (see also De Cremer \& Van Dijk, 2002; Kramer \& Goldman, 1995; van Knippenberg, 2000), we predicted that our identification measure, which reflects a sense of collective self, rather than positive expectations, mediates the effect of identification that in earlier studies was found to be moderated by SVO. Finding both evidence for the interactive effect between SVO and identification, and the mediating effect of a sense of collective self reflected in identification would provide unambiguous evidence in favor of the goal-transformation hypothesis.

Furthermore, and contrary to the assumptions of the goal-amplification hypothesis, we expected that expectations, rather than a sense of collective self, mediate the main effect of SVO (i.e., more cooperation by prosocials than by proselfs). This 
prediction is derived from research that has demonstrated that prosocials, relative to proselfs, exhibit the same level of cooperation as they expect from others (see Van Lange \& Kuhlman, 1994). Because prosocials are generally more cooperative than proselfs (e.g. De Cremer \& Van Lange, 2001), their expectations about other's behavior are assumed to be more positive.

Finally, another aspect that distinguishes the present research from the earlier mentioned studies is that we used another type of identification manipulation. In these earlier studies, identification was manipulated by introducing a social comparison between one’s own group and another group to enhance feelings of group identification (i.e., social competition; Turner, 1975). One aspect of this social comparison manipulation is that the notion of competition becomes very pervasive, and consequently people may cooperate more with their own group due to motives related to winning this competition, rather than experiencing a strong sense of collective self. Therefore, to further validate and generalize the discussed identification effect, we used an identification manipulation that varied self-ingroup similarity, which is assumed to be a key determinant of identification (e.g., Hogg \& Abrams, 1988; Turner, 1987) rather than intergroup comparison/competition.

Method

\section{Participants and Design}

One hundred and eight undergraduate students from several different majors from the University of Amsterdam (40 men, 68 women; mean age 20.59) were randomly assigned to either the high or the low identification condition, and classified as either proself of prosocial on the basis of an SVO measure (see below). This yielded a 2 (SVO: 
prosocials vs. proselfs) x 2 (Identification: high vs. low) between-subjects factorial design, with cell sizes varying from 20 to 26 participants.

\section{Procedure}

Upon arrival in the laboratory, each participant was seated in a separate cubicle that contained a computer, a table, and a chair. All instructions were given via the computer. Before explaining the purpose of the study, each participant was allocated an experimental letter. Participants (five per session) believed that they would get a unique letter (A, B, C, D, or E). In reality, each participant got the letter D.

Assessment of social value orientation. As a first task, they completed a computerized version of the nine-item Decomposed Games measure to assess their social value orientation (Messick \& McClintock, 1968; Van Lange \& Kuhlman, 1994). The Decomposed Games instrument has excellent psychometric qualities. It is internally consistent (e.g. Liebrand \& Van Run, 1985; Parks, 1994), reliable over substantial time periods (Eisenberger, Kuhlman, \& Cotterell, 1992), and is not related to measures of social desirability or indices of mood (e.g., Kuhlman, Camac, \& Cunha, 1986; Platow, 1992; Van Lange, Otten, De Bruin, \& Joireman, 1997; Van Lange \& Liebrand, 1991). Moreover, there is evidence for its ecological validity in various domains (e.g., De Dreu \& Van Lange, 1995; Van Lange, Van Vugt, Meertens, \& Ruiter, 1998; Van Vugt et al., 1995).

The task consists of nine items, each containing three alternative outcome distributions with points for oneself and an (anonymous) other. Each outcome distribution represents a particular orientation. An example is the choice between alternative A: 500 points for self and 500 points for other, B: 560 points for self and 300 for other; and C: 500 points for self and 100 for other. Option A represents the cooperative or prosocial 
orientation, because it provides an equal distribution of outcomes (i.e., 500 for self and other). Option B represents the individualistic option because own outcomes are maximized (560 versus choice A and C, i.e., both 500) irrelative of other's outcomes. Finally, option C represents the competitive orientation because this distribution maximizes the difference between own outcome and other's outcomes (Choice C: $500-100=400$, versus A: 500 $500=0$, and B: $560-300=260)$.

Participants are classified as prosocial, individualistic or competitive when at least six choices (out of nine) are consistent with one of the three orientations (e.g., McClintock \& Allison, 1989; Van Lange \& Kuhlman, 1994). In the present study we only used the comparison between prosocials and individualists, because the group of competitors was considered too small for subsequent analyses. ${ }^{1}$ Therefore, out of a total number of 108 individuals, 46 (43 \%) were identified as prosocials, and 42 (39\%) as individualists.

Introduction to the public good dilemma. After completing the decomposed games, participants were introduced to a decision-making study in small groups consisting of five persons each. They were told that they would be participating in a collective-decision making task in which they would be asked several times to contribute toward the establishment of a public good. To avoid endplay, no specific number of contribution sessions was mentioned (Murnighan \& Roth, 1983). More specifically, each participant was given an endowment of 100 chips, worth each 5 euro cents, at the beginning of each contribution session, and they were free to choose any amount they wanted to contribute (ranging from 0 to 100 chips). It was explained that the total amount contributed by the group would be multiplied by two and then divided equally among all group members. The number of chips that one did not contribute to the group 
would accrue totally to oneself. All of this was illustrated with various examples of possible outcome distributions.

Manipulation of group identification. To manipulate group identification, we gave participants bogus feedback about the composition of their group. In the high identification condition, participants learned that all but one member of their group had the same study major as the participant him or herself. In the low identification condition, participants learned that all other members of their group had the same study major, which was different from participants own major. In this way, the group was equally homogeneous in terms of study major (four members with the same major, one with a different major) across conditions, while the similarity between the participant and the group varied across conditions.

Then, the dependent variables of this study were solicited. First, participants' level of group identification was assessed by five items reflecting the degree to which one has a sense of collective self (Van Leeuwen, van Knippenberg, \& Ellemers, 2000). Items include "I see myself as a typical member of this group", and "I feel a tie with this group” (answers on 7-point scales with endpoints labeled absolutely not [1] and very much so [7]). Thereafter, participants were asked how much they were willing to contribute (ranging from 0 to 100 points). Finally, participants' expectations about other's cooperative intentions were measured by asking them how much they expected the others to contribute.

Results

\section{Identification}

Testifying to the success of the identification manipulation, a 2 x 2 ANOVA on the 
identification measure revealed a main effect of Identification, $F(1,84)=10.32, p<.005$, showing that sense of a collective self was higher $(M=3.96)$ in the high identification condition than in the low identification condition $(M=3.10)$. Neither the SVO main effect, $F(1,84)=0.49$, ns., nor the interaction, $F(1,84)=0.04$, ns., affected identification.

Contributions

A 2 x 2 ANOVA on contributions revealed, first of all, a main effect of SVO, $F(1$, $84)=3.86, p=.05$. Overall, prosocials contributed more $(M=61.21)$ than proselfs $(M=$ 47.24). The main effect of identification was not significant, $F(1,84)=0.31$, $n s$, but the predicted Identification by SVO interaction was, $F(1,84)=4.49, p<.05$ (see Table 1 ). Tests of simple main effects showed that when identification was low, prosocials contributed more than proselfs, $F(1,84)=9.13, p<.003$, but when identification was high, proselfs contributed as much as prosocials, $F(1,84)=0.01$, $n s$. In a similar vein, test of the simple main effects of Identification showed that this was marginally significant for proselfs, $F(1,84)=3.44, p<.07$, but nonsignificant for prosocials, $F(1$, $84)=1.27, n s$.

Expected contributions

A $2 \times 2$ ANOVA on the contribution expected from the other members of the group, revealed only a significant main effect of SVO, $F(1,84)=4.75, p<.05$ :

Prosocials expected higher contributions $(M=51.91)$ than proselfs $(M=39.41)$. Neither the Identification main effect, $F(1,84)<1$, ns., nor the interaction, $F(1,84)<1$, ns., were significant.

Mediational analysis 
Because Identification did not affect expectations of others' cooperation, we can rule out the goal-amplification account of the identification effect. However, it remains important to establish whether the effect of our identification manipulation is mediated by our the sense of collective self reflected in our measure of identification, as the goaltransformation hypothesis predicts--if only to rule out other, alternative explanations (i.e., self-group similarity might affect other, unmeasured, variables as well). Put differently, we know that our manipulation affected the sense of collective self reflected in our measure of identification, but is this also the reason why the Identification manipulation and SVO interacted in affecting contributions? To address this issue, we conducted a mediational analysis.

In the "conventional" mediational analysis, the aim is to test whether a main or interaction effect obtained is mediated by the main effect of the mediator variable. Adding the mediator variable to the ANOVA design or the regression equation and showing that the effect of the mediator is significant whereas the to-be-mediated effect no longer is, is then the final step in the mediation analysis (after showing that the to-bemediated effect affects the mediator and the outcome variable; Baron \& Kenny, 1986). In the present case, however, we do not propose that measured identification mediates the Identification x SVO interaction (which could be tested in a convential mediational analysis), but rather that measured identification mediates the effect of manipulated identification in the Identification x SVO interaction. That is, we need to show that the moderating effect of manipulated identification on SVO is explained by measured identification. This requires a slightly more complicated mediational analysis that is explained by Hull, Tedlie, and Lehn (1992). Applying their technique, we need to show 
that the interaction of measured identification (i.e., participants' identification scores) and SVO mediates the interaction of manipulated identification and SVO. To test this prediction, we entered the measure of identification to an ANCOVA design as a continuous variable and tested both the measured identification main effect and the SVO by measured identification interaction. In addition, in this ANCOVA, also the main effects of our Identification manipulation and SVO and the Identification manipulation by SVO interaction were tested.

In line with our predictions, the measured identification by SVO interaction was significant, $F(1,82)=6.42, p<.05$, whereas the (manipulated) Identification by SVO interaction was no longer significant, $F(1,82)=1.52, p>.20$. Importantly, the main effect of SVO remained significant, $F(1,82)=9.06, p<.005$. Interestingly, whereas the main effect of our identification manipulation was not significant in the original analysis nor in the present analysis, $F(1,82)=0.18$, ns., the main effect of measured identification was, $F(1,82)=7.92, p<.01$. Inspection of the regression weights for the effects of measured identification showed that higher identification was associated with higher contributions ( $\beta=.29$ for the identification main effect) and that this relationship was weaker for prosocials than for proselfs ( $\beta=-.26$ for the interaction). Tests of the simple main effects of measured identification for each level of SVO further confirmed our predictions (i.e., supporting the goal-transformation hypothesis). The simple effect of measured identification was significant and positive for proselfs, $\beta=.38, F(1,82)=$ 13.63, $p<.0001$, but not significant for prosocials, $\beta=.02, F(1,82)=0.04$, ns. We may thus conclude that a sense of collective self mediated the effect of our Identification manipulation in the Identification by SVO interaction, but not the main effect of SVO. 
The second issue we raised was the role of expectations of others' contributions. We proposed that these expectations would mediate the main effect of SVO, but because we did not find any evidence in support of the goal-amplification hypothesis (i.e., expectations as an explanation for the identification effect in social dilemmas) we did not predict it to mediate the Identification by SVO interaction. To examine whether this was true, we tested this prediction in a second mediational analysis in which we again followed the analysis of Hull et al. (1992). That is, in addition to the SVO main effect and the manipulated Identification x SVO interaction, we added both the expected contributions main effect and the manipulated Identification by expected contributions interaction to our ANCOVA design. Results revealed that the main effect of expected contributions was significant, $\beta=.80, F(1,82)=150.25, p<.0001$, whereas the SVO main effect was no longer significant, $F(1,82)=0.17$, ns. Further, if the goalamplification hypothesis is not valid, the manipulated Identification x SVO interaction should remain significant. In line with this, ANCOVA indeed showed that the expected contributions by Identification interaction was not significant, $F(1,82)=1.34, p>.25$, and that, most importantly, the Identification by SVO interaction remained significant, $F(1,82)=6.21, p<.025$. We may therefore conclude that expected contributions mediated the main effect of SVO, but not the Identification by SVO interaction.

\section{Discussion and Conclusions}

The fact that a social identification influences level of cooperation suggests a socialized conception of decision-making (Kramer \& Goldman, 1995), but how actually does it work? Following the present findings, a goal-transformation explanation seems to account best for these social identification effects. Indeed, in line with previous studies, 
we found a significant interaction between identification and SVO, showing that proselfs were influenced more by the identification manipulation than prosocials. Furthermore, and more importantly, our mediational analyses demonstrated that a sense of collective self, and not participants' expectations, mediated the identification effect that was moderated by SVO. In the following paragraphs, we will discuss these findings in greater detail.

The present findings provide strong support for our prediction that social identification effects in social dilemmas can be explained by people’s tendency to include the group and its goals into the self (i.e., goal-transformation hypothesis). Taken together, the fact that the identification effect was only found among proselfs (who assign more weight to outcomes for the self relative to those for the group) and that the effect of the identification manipulation was mediated by a measure of identification operationalized as a sense of collective self can be seen as compelling evidence that the primary mechanism responsible for the social identification effect is the transformation of personal goals into collective-based goals (i.e., a sense of collective self). Using the terminology of interdependence theory (Kelley \& Thibaut, 1978), enhancing one’s sense of collective self thus seems to transform an existing situation with a given payoff to self and others (i.e., objective matrix) into another situation, which directs decisions on the basis of more broader and collective goals (i.e., effective matrix). As such, our findings add evidence to a growing number of studies advocating the goal-transformation hypothesis as a primary explanation of the social identification effect (De Cremer \& Van Vugt, 1999; De Cremer \& Van Dijk, 2002; van Knippenberg, 2000). 
These results align well with Self-Categorization Theory (SCT; Turner et al., 1987). Following SCT, level of identification may depend on the degree of self-group similarity or perceptions of homogeneity within the group perceived by the group members (e.g. Hogg \& Abrams, 1988; Turner, 1987). When perceived similarity between self and the group is low, people's sense of self is defined at the level of the individual, whereas they will define themselves at the collective level when self-group similarity is high. More specifically, if this similarity is high, people will use their group membership and sense of a collective self to define themselves and their concurrent goals (Turner, 1982). In accord with SCT, our manipulation of group identification influenced the self-perception of proselfs in such a way as to cause a shift from the personal level towards the higher, more inclusive group level ("me” becomes "we”-identity). As a consequence, our interpretation (in favor of the goal-transformation hypothesis) as such implies that self-interest can be defined at many different levels, from narrow personal interest to the interest of the collective (i.e., different levels of abstraction, see Turner et al., 1987). If a collective self is reinforced, the self-interest at the personal level is transformed to self-interest at the collective level, and cooperation becomes the "rational" choice (Turner et al., 1987).

Contrary to the goal-amplification hypothesis, prosocials remained largely insensitive to the group identification manipulations. Why may this be? One explanation is that prosocials have more positive expectations about others than proselfs do, and they are therefore less sensitive to information, which further enhances their trust in others' cooperation. Contrary to this intuitively compelling assumption, however, previous studies have mainly failed in finding a relationship between SVO and positive 
expectations (Parks, 1994; Van Lange et al., 1998; for an exception see Kuhlman, Camac, \& Cunha, 1986). For example, it has been found that prosocials and proselfs do not differ significantly in dispositions of general trust (Parks, 1994). Indeed, these studies suggest that rather than expecting reciprocity, it seems that prosocials engage in cooperation because they believe it is the morally right thing to do (Beggan, Messick \& Allison, 1988; Sattler \& Kerr, 1991; Van Lange \& Liebrand, 1991). In this sense, prosocials can be regarded as "genuine" cooperators who cooperate for a particular collective cause, regardless of whether other individuals do the same (Van Lange et al., 1998). Despite these claims, our mediational findings do show that expectations mediated the main effect of SVO. This observation shows some similarities to previous research by Van Lange and Kuhlman (1994), who assumed and partly demonstrated that prosocials, relative to proselfs, exhibit the same level of cooperation as they expect from others. As such, expectations or, in other words trust in others' cooperative intentions, do seem to be related to the actions of prosocials in decision-making situations. Thus, the frequently observed effect of SVO in social dilemmas may be related to another important psychological factor in social dilemmas, that is, expectations.

Before closing, some limitations and strengths need to be outlined. An important potential limitation is that we measured participants' expectations after they had made their decision. As a consequence, expectations may have been influenced by the main outcome variable cooperation (i.e., reverse causal effects, Kenny, Kashy, \& Bolger, 1998) in a way that responding to the expectations item involved some type of “dissonance reduction” to justify their prior decision. However, if this would be true than we should have found that expectations mediated all effects (including the interaction), 
but this was not the case. In fact, only the main effect of SVO was mediated by expectations. An important strength is that we were able to demonstrate strong and compelling evidence, by means of a moderator and mediating approach, in favor of the goal-transformation hypothesis. Moreover, the fact that we also used a different manipulation of group identification than prior studies supporting this hypothesis, validates and generalizes the observed identification effect in social dilemmas and allows us to be even more confident about the prediction that social identification in social dilemmas enhances one's sense of collective self.

Taken together, the present findings are in line with a theoretical account advocating that the primary reason why social identification influences levels of cooperation in social dilemmas is because decision-makers' include the group and its goals into the self (i.e., collective self) and are therefore motivated to pursue the collective welfare. As such, these findings illustrate the importance of motivational processes in decision-making as a function of the extent to which one feels included in the collective. If this sense of inclusion is salient then goals are triggered that serve to collective. Thus, it can be concluded that cooperation seems to emerge, at least partly, from collective-based goals. 


\section{References}

Baron, R.M., \& Kenny, D.A. (1986). The moderator-mediator distinction in social psychological research: Conceptual, strategic, and statistical considerations. Journal of Personality and Social Psychology, 51, 1173-1182.

Beggan, J.K., Messick, D.M., \& Allison, S.T. (1988). Social values and egocentric bias: Two tests of the might over morality hypothesis. Journal of Personality and Social Psychology, 55, 606-611.

Brewer, M. B. (1979). In-group bias in the minimal group intergroup situation: A cognitive-motivational analysis. Psychological Bulletin, 86, 307-324.

Brewer, M.B. (1981). Ethnocentrism and its role in interpersonal trust. In M.B. Brewer, \& B.E. Collins (Eds.), Scientific inquiry and the social sciences (pp. 345-360). New York: Jossey-Bass.

Brewer, M.B., \& Gardner, W. (1996). Who is this “we”? Levels of collective identity and self representations. Journal of Personality and Social Psychology, 71, 83-83.

Brewer, M. (1991). The social self: On being the same and different at the same time. Personality and Social Psychology Bulletin, 17, 475-482.

Brewer, M.B., \& Kramer, R.M. (1986). Choice behavior in social dilemmas: Effects of social identity, group size and decision framing. Journal of Personality and Social Psychology, 50, 543-549.

Brewer, M.B., \& Schneider, S.K. (1990). Social identity and social dilemmas: A double-edged sword. In D. Abrams, \& M.A. Hogg (Eds.), Social identity theory: Constructive and critical advances (pp. 169-184). Harvester, Wheatsheaf. 
Dawes, R. M. (1980). Social dilemmas. Annual Review of Psychology, 31, 169193.

De Cremer, D., Snyder, M., \& Dewitte, S. (2001). The less I trust, the less I contribute (or not?): Effects of trust, accountability and self-monitoring in social dilemmas. European Journal of Social Psychology, 31, 91-107.

De Cremer, D., \& van Dijk, E. (2002). Reactions to Group Success and Failure as a Function of Group Identification: A Test of the Goal-Transformation Hypothesis in Social Dilemmas. Journal of Experimental Social Psychology, 38, 435-442.

De Cremer, D., \& van Lange, P. A. M. (2001). Why prosocials exhibit greater cooperation than proselfs: The role of responsibility and reciprocity. European Journal of Personality, 15, S1, 5-18.

De Cremer, D., \& Van Vugt, M. (1999). Social identification effects in social dilemmas: A transformation of motives. European Journal of Social Psychology, 29, 871893.

De Dreu, C.K.W., \& Van Lange, P.A.M. (1995). Impact of social value orientations on negotiator cognition and behavior. Personality and Social Psychology Bulletin, 21, 11781188.

Edney, J.J. (1980). The commons problem: alternative perspectives. American Psychologist, 35, 131-150.

Eisenberger, R., Kuhlman, D.M., \& Cotterell, N. (1992). Effects of social values, effort training, and goal structure on task persistence. Journal of Research in Personality, 26, 258-272. 
Hogg, M. A., \& Abrams, D. (1988). Social identifications: A social psychology of intergroup relations and group processes. London: Routledge.

Hull, J. G., Tedlie, J. C., \& Lehn, D. A. (1992). Moderator variables in personality research: The problem of controlling for plausible alternatives. Personality and Social Psychology Bulletin, 18, 115-117.

Kelley, H. H., \& Stahelski, A. J. (1970). Social interaction basis of cooperators’and competitors’beliefs about others. Journal of Personality and Social Psychology, 16, 66-91.

Kelley, H.H., \& Thibaut, J.W. (1978). Interpersonal relations: A theory of interdependence. New York: Wiley.

Kenny, D. A., Kashy, D. A., \& Bolger, N. (1998). Data analysis in social psychology. In D. T. Gilbert, Fiske, S. T., \& Lindzey, G. (Eds.), The handbook of social psychology (pp. 233-268). New York: Oxford University Press.

Kerr, N. (1983). Motivation losses in small groups. A social dilemma analysis. Journal of Personality and Social Psychology, 45, 819-828.

Komorita, S. S., \& Parks, C. D. (1994). Social dilemmas. Dubuque, IA: Brown \& Benchmark.

Kramer, R. M., \& Brewer, M. B. (1984). Effects of group identity on resource use in a simulated commons dilemma. Journal of Personality and Social Psychology, 46, 10441057.

Kramer, R.M., \& Goldman, L. (1995). Helping the group or helping yourself? Social motives and group identity in resource dilemmas. In D.A. Schroeder (Ed.), Social dilemmas: Perspectives on individuals and groups (pp. 49-67). Praeger, Westport, Connecticut London. 
Kuhlman, D.M., Camac, C., \& Cunha, D.A. (1986). Individual differences in social value orientation. In H. Wilke, D. Messick, \& C. Rutte (Eds.), Experimental social dilemmas (pp. 151-176). New York: Verlag Peter Lang.

Liebrand, W.B.G., \& van Run, G.J. (1985). The effects of social motives on behavior in social dilemmas in two cultures. Journal of Experimental Social Psychology, 21, 86-102.

Luce, R. D., \& Raiffa, H. (1957). Games and decisions: Introduction and critical survey. London: John Wiley and Sons.

McClintock, C. G. (1972). Social motivation — a set of propositions. Behavioral Science, $17,438-454$.

McClintock, C.G., \& Allison, S.T. (1989). Social value orientation and helping behavior. Journal of Applied Social Psychology, 19, 353-362.

Messick, D. M., \& Brewer, M. B. (1983). Solving social dilemmas. In L. Wheeler \& P. R. Shaver (Eds.), Review of personality and social psychology (Vol. 4, pp. 11-44). Newbury Park, CA: Sage.

Messick, D. M., \& McClintock, C. G. (1968). Motivational basis of choice in experimental games. Journal of Experimental and Social Psychology, 4, 1-25.

Murnighan, J. K., \& Roth, A. E. R. (1983). Expecting continued play in prisoner's dilemma games: A test of several models. Journal of Conflict Resolution, 27, 279-300.

Parks, C. D. (1994). The predictive ability of social values in resource dilemmas and public goods games. Personality and Social Psychology Bulletin, 20, 431-438.

Platow, M. J. (1992). An evaluation of the social desirability of social self-other allocation choices. Journal of Social Psychology, 134, 61-68. 
Pruitt, D. G., \& Kimmel, M. (1977). Twenty years of experimental gaming:

Critique, synthesis, and suggestions for the future. Annual Review of Psychology, 28, 363392.

Rapoport, A. (1967). A note on the index of cooperation for prisoner's dilemma. Journal of Conflict Resolution, 11, 101-103.

Sattler, D.N., \& Kerr, N.L. (1991). Might versus morality explored: Motivational and cognitive bases for social motives. Journal of Personality and Social Psychology, 60, 756-765.

Shepperd, J. A. (1993). Productivity loss in performance groups: A motivation analysis. Psychological Bulletin, 113, 67-81.

Smith, E., \& Henry, S. (1996). An in-group becomes part of the self: response time evidence. Personality and Social Psychology Bulletin, 22, 635-642.

Tajfel, H., \& Turner, J.C. (1986). The social identity theory of intergroup behavior. In S. Worchel \& W. Austin (Eds.), Psychology of intergroup relations (pp. 7-24) Chicago: Nelson-Hall.

Turner, J. C. (1975). Social comparison and social identity: Some prospects for intergroup behavior. European Journal of Social Psychology, 5, 5-34.

Turner, J.C. (1982). Towards a cognitive redefinition of the social group. In H. Tajfel (Ed.), Social identity and intergroup relations (pp. 15-40). Cambridge: Cambridge University Press

Turner, J. C. (1987). A self-categorization theory. In J. C. Turner, M. A. Hogg, P. J. Oakes, S. D. Reicher, \& M. Wetherell (Eds.), Rediscovering the social group: A selfcategorization theory (pp. 42-67). Oxford: Basil Blackwell. 
Turner, J. C., Hogg, M. A., Oakes, P. J., Reicher, S. D., \& Wetherell, M. (1987). Rediscovering the social group: A self-categorization theory. Oxford: Basil Blackwell.

Van Lange, PAM. 1999. The pursuit of joint outcomes an equality in outcomes: An integrative model of social value orientation. Journal of Personality and Social Psychology, 77, 337-349.

Van Lange, P. A. M., \& Kuhlman, D. M. (1994). Social value orientations and impressions of partner's honesty and intelligence: A test of the might versus morality effect. Journal of Personality and Social Psychology, 67, 126-141.

Van Lange, P.A.M., \& Liebrand, W.B.G. (1991). Social Value Orientation and Intelligence: A test of the goal-prescribes-rationality principle. European Journal of Social Psychology, 21, 273-292.

Van Lange, P.A.M., Otten, W., De Bruin, E.N.M., \& Joireman, J.A. (1997). Development of prosocial, individualistic, and competitive orientations: Theory and preliminary evidence. Journal of Personality and Social Psychology, 73, 733-746.

Van Lange, P.A.M., Van Vugt, M., Meertens, R.M., \& Ruiter, R.A.C. (1998). A social dilemma analysis of commuting preferences: The roles of social value orientation and trust. Journal of Applied Social Psychology, 28, 796-820.

van Knippenberg, D. (2000). Work motivation and performance: A social identity perspective. Applied Psychology: An International Review, 49, 357-371.

van Knippenberg, D., \& Ellemers, N. (in press). Social identity and group performance: Identification as the key to group-oriented efforts. In S. A. Haslam, D. van Knippenberg, M. J. Platow, \& N. Ellemers (Eds.), Social identity at work: Developing theory for organizational practice. Philadelphia, PA: Psychology Press. 
Van Leeuwen, E., \& van Knippenberg, D. (2002). How a group goal can reduce matching in group performance: Shifts in standards for determining a fair contribution of effort. The Journal of Social Psychology, 142 , 73-86.

Van Leeuwen, E., van Knippenberg, D., \& Ellemers, N. (2000, July). Preserving identity in times of change: The effects of subgroup distinctiveness in asymmetric mergers. Paper presented at the EAESP Small Group Meeting on Social Identity Processes in Organizations, Amsterdam.

Van Vugt, M., Van Lange, P.A.M., \& Meertens, R.M. (1995). Car versus public transportation? The role of social value orientations in a real-life social dilemma. Journal of Applied Social Psychology, 25, 258-278.

Wit, A.P., \& Wilke, H.A.M. (1992). The effect of social categorization on cooperation in three types of social dilemmas. Journal of Economic Psychology, 13, 135151. 


\section{Footnote}

${ }^{1}$ We are aware that some previous research combined individualists and competitors into one group of proselfs. However, because a social dilemma constitutes a clear conflict between one's own personal interest and the collective interest, we decided to compare cooperators (i.e., prosocials) with individualists (i.e., proselfs) in our analyses, because the motives of these two types of individuals represent best this conflict between interests and as such allows for an unambiguous interpretation of our findings. 
Table 1.

Group Identification, Contributions, and Expected Contributions as a Function of Social Value Orientation and Identification

\begin{tabular}{|c|c|c|c|}
\hline \multirow{2}{*}{$\begin{array}{l}\text { Dependent } \\
\text { Variables }\end{array}$} & \multirow[b]{2}{*}{ SVO } & \multicolumn{2}{|c|}{ Identification } \\
\hline & & High & Low \\
\hline Group & Prosocial & 4.02 (1.23) & 3.22 (1.25) \\
\hline Identification & Proself & 3.89 (1.01) & $2.98(1.41)$ \\
\hline \multirow[t]{2}{*}{ Contributions } & Prosocial & 55.65 (30.19) & $66.77(31.40)$ \\
\hline & Proself & 56.57 (36.90) & $37.73(34.26)$ \\
\hline Expected & Prosocial & $48.25(20.54)$ & 55.58 (25.97) \\
\hline Contributions & Proself & 41.00 (29.67) & 37.82 (29.67) \\
\hline \multicolumn{4}{|c|}{ Note. Entries are means on 7-point scales and contributions that could range from $0 \mathrm{t}$} \\
\hline 100 points, witl & her value & iigher identific & utions and \\
\hline
\end{tabular}


Biographical notes authors

David De Cremer is associate professor at the department of experimental psychology, Maastricht University, the Netherlands and is currently a fellow of the Netherlands Organization for Scientific Research (NWO). His main research interests include decision-making, social dilemmas, leadership, the psychology of distribution rules, and the relationship between self and procedural justice.

Daan van Knippenberg is professor of organizational behavior at the Rotterdam School of Management, Erasmus University Rotterdam, the Netherlands. His main research interests include leadership, group performance, organizational diversity, and group decision-making.

Eric van Dijk is professor of social psychology at the department of social and organizational psychology, Leiden University, the Netherlands. His main research interests include social dilemmas, bargaining, coalition formation, behavioral economics, and the role of emotions in decision-making.

Esther van Leeuwen is assistant professor at the department of social psychology, Free University Amsterdam, the Netherlands. Her research interests are: mergers, subgroup relations, and prosocial behavior. 


\section{Publications in the ERIM Report Series Research* in Management}

\section{ERIM Research Program: "Organizing for Performance"}

2007

Leadership Behaviour and Upward Feedback: Findings From a Longitudinal Intervention

Dirk van Dierendonck, Clare Haynes, Carol Borrill and Chris Stride

ERS-2007-003-ORG

http://hdl.handle.net/1765/8579

The Clean Development Mechanism: Institutionalizing New Power Relations

Bettina B.F. Wittneben

ERS-2007-004-ORG

http://hdl.handle.net/1765/8582

How Today's Consumers Perceive Tomorrow's Smart Products

Serge A. Rijsdijk and Erik Jan Hultink

ERS-2007-005-ORG

Product Intelligence: Its Conceptualization, Measurement and Impact on Consumer Satisfaction

Serge A. Rijsdijk, Erik Jan Hultink and Adamantios Diamantopoulos

ERS-2007-006-ORG

http://hdl.handle.net/1765/8580

Testing the Strength of the Iron Cage: A Meta-Analysis of Neo-Institutional Theory

Pursey P.M.A.R. Heugens and Michel Lander

ERS-2007-007-ORG

http://hdl.handle.net/1765/8581

Export Orientation among New Ventures and Economic Growth

S. Jolanda A. Hessels and André van Stel

ERS-2007-008-ORG

http://hdl.handle.net/1765/8583

Allocation and Productivity of Time in New Ventures of Female and Male Entrepreneurs Ingrid Verheul, Martin Carree and Roy Thurik

ERS-2007-009-ORG

Cooperating if one's Goals are Collective-Based: Social Identification Effects in Social Dilemmas as a Function of Goal-Transformation David De Cremer, Daan van Knippenberg, Eric van Dijk and Esther van Leeuwen

ERS-2007-010-ORG

* A complete overview of the ERIM Report Series Research in Management: https://ep.eur.nl/handle/1765/1

ERIM Research Programs:

LIS Business Processes, Logistics and Information Systems

ORG Organizing for Performance

MKT Marketing

F\&A Finance and Accounting

STR Strategy and Entrepreneurship 